\title{
Parameters Identification of Induction Motor Model Based on Manufacturer Data and Sequential Quadratic Programming
}

\author{
Weiping Liao*, Yan Zhang, Rui Zhou \\ Jiangmen Power Supply Bureau, Guangdong Power Grid Co., Ltd., Jiangmen, China
}

Email address:

1071672259@qq.com (Weiping Liao)

*Corresponding author

\section{To cite this article:}

Wei-ping Liao, Yan Zhang, Rui Zhou. Parameters Identification of Induction Motor Model Based on Manufacturer Data and Sequential Quadratic Programming. Automation, Control and Intelligent Systems. Vol. 6, No. 3, 2018, pp. 28-37. doi: 10.11648/j.acis.20180603.11

Received: June 24, 2018; Accepted: July 25, 2018; Published: December 18, 2018

\begin{abstract}
In order to precaution and control the transient voltage stability of the receiving-end system, it is very necessary to quickly and accurately calculate the model parameters for induction motor synthesis load. There are several methods to obtain the model parameters of induction motor, in which, estimating the model parameters of induction motor using for power system stability analysis according to the nameplate data is a significant promising approach with potential application. In this paper, a new optimized mathematical model for identification of induction motor single-cage and double-cage parameters are proposed, it's overcome the deficiency of artificially adding approximate constraints in parameter identification of induction motor models from induction motor manufacturer data. Minimization of the induction motor efficiency deviation is taken as the goal and important induction motor performance indicators, such as the stator current, the input reactive power, the maximum electromagnetic torque and the starting parameters, are equal to their manufacturer values are regarded as constraints, the sequential quadratic programming (SQP) is used to solve the nonlinear problem. The proposed new mathematical model and algorithm were verifed on a sample of 6 induction motors of different capacity, manufacturers, and rated voltage. The induction motor performance characteristics supplied by the manufacturer and used to identification parameters of induction motor are then calculated, using the equivalent circuit estimated parameters themselves. In all the studied cases, the calculated induction motors performance indexes are found to be in excellent agreement with the manufacturer data. Comparison with other methods shows that the induction motor model parameters obtained by this method can reflect the working characteristics of induction motor single-cage and double-cage model more accurately.
\end{abstract}

Keywords: Induction Motor, Manufacturer Data, Parameter Identification, Sequential Quadratic Programming

\section{Introduction}

With the implementation and deepening of the "west-east power transmission" strategy, China has gradually formed a number of large receiving terminal systems such as Beijing, Shanghai and Guangzhou. A large proportion of power from the sending system is delivered to the receiving system, and the high proportion of constant power characteristic loads such as air conditioning, make the problem of voltage stability become more and more prominent $[1,2]$.

In essentially, the voltage stability is a dynamic problem, and many dynamic factors play an important role for voltage stability in the power system. Among them, load characteristics have a significant effect on voltage stability [3], and accuracy of load model and parameters have become the key factors for voltage stability analysis of power system [4].

Induction motors occupies a large proportion in the load of power system. The synthesis load adopts the parallel model of induction motor and static load in many software packages of power system calculation and analysis. Experimental measurement is the most accurate way to get the model parameters of induction motor, but it is limited in application because a large number of categories and quantity of induction motor loads in the power system [5]. It's a great potential method to estimates induction motor model parameters for power system analysis and calculation through the induction 
motor manufacturer data (such as rated power, rated current, maximum electromagnetic torque, etc.) [8]-[13].

ATP/EMTP and PSCAD/EMTDC of power system electromagnetic transient analysis software calculate induction motor double-cage model parameter with the method in [9]. However, this method does not use the maximum electromagnetic torque multiple of the induction motor, which is an important parameter to express the overload performance index of the induction motor. In [8], it considers maximum electro- magnetic torque multiple, and uses the iterative method to solve the single-cage model parameters of induction motor, it is approximately assumed that the stator reactance $X_{\mathrm{s}}=X_{\mathrm{r}}$. In [10]-[12], it is also assumed that $X_{\mathrm{s}}=X_{\mathrm{r}}$, and establishes an optimized identification model with the minimum deviation between the important performance index and manufacturer value of the induction motor as the objective function, but the performance indicators calculated according to the identification parameters are not satisfactory. In paper [13], the maximum electromagnetic torque, starting torque and starting current have been taken into consideration, and calculates the double-cage model parameters of the induction motor by solving nonlinear equations with Newton Raphson method. It is considered that the stator resistance $R_{\mathrm{s}}$ and reactance $X_{\mathrm{s}}$ are proportional to the cage parameters $R_{\mathrm{r} 1}$ and $X_{\mathrm{r} 1}$ of the rotor, however, the induction motor parameters obtained are not ideal. Above all, it can be seen that the accurate calculation of induction motor model parameters based on manufacturer data has not been solved well yet.

This paper establishes a new optimization model for induction motor model identification parameters based on the analysis of induction motor manufacturer data. The new model was solved by sequential quadratic programming algorithm, and the parameters of single-cage and double-cage models were obtained. Taking the identification parameters of multiple induction motors as an example, the validity of the proposed model and algorithm is verified.

\section{Induction Motor Model and Manufacturer Data}

Generally, the single-cage model is adopted for winding and single-cage induction motors shown in Figure 1(a), while the double-cage model is adopted for deep-groove and double-cage induction motors shown in Figure 1(b). In order to simulate the starting characteris- tics accurately, it is advisable to replace the single-cage model with the double-cage model [8].

In Figure $1, U_{\mathrm{s}}$ is terminal voltage, $s$ is slip, $R_{\mathrm{s}}$ and $X_{\mathrm{s}}$ are stator resistance and reactance in the double-cage model, $X_{\mathrm{m}}$ is excitation reactance in the double-cage model, $R \mathrm{r}$ and $X \mathrm{r}$ are rotor resistance and reactance of single-cage model. $R_{\mathrm{r} 1}$ and $X_{\mathrm{r} 1}$ are inner cage resistance and reactance in the double-cage model, and $R_{\mathrm{r} 2}$ and $X_{\mathrm{r} 2}$ are outer cage resistance and reactance in the double-cage model. Generally, $R_{\mathrm{r} 1}<R_{\mathrm{r} 2}, X_{\mathrm{r} 1}>X_{\mathrm{r} 2}$. When it's starting, the outer cage plays a major role so that the frequency of rotor current is high, the inner current is small, the power factor is lower, and also producing small electromagnetic torque. When it's working normally, the rotor current frequency decreases, and the inner cage current is large, inner cage plays a major role. Therefore, the double-cage model can simulate the starting characteristics of induction motor more accurately [15].

The manufacturer data of Induction motor includes: rated mechanical power $P_{\mathrm{n}}(\mathrm{kW})$, rated voltage $U_{\mathrm{n}}(\mathrm{kV})$, rated current $I_{\mathrm{n}}(\mathrm{A})$, rated speed $n_{\mathrm{n}}(\mathrm{r} / \mathrm{min})$, rated efficiency $\eta_{\mathrm{n}}(\%)$, rated power factor $\cos \theta_{\mathrm{n}}$, the maximum torque of multiple $K_{\mathrm{m}}$ ( $K_{\mathrm{m}}=T_{\mathrm{em}} / T_{\mathrm{n}}, T_{\mathrm{em}}$ for maximum or critical electromagnetic torque, $T_{\mathrm{n}}$ is rated torque), starting torque multiple $K_{\mathrm{st}}$ ( $K_{\mathrm{st}}=T_{\mathrm{st}} / T_{\mathrm{n}}, T_{\mathrm{st}}$ is starting torque), starting current multiple $K_{\text {Ist }}\left(K_{\text {Ist }}=I_{\text {st }} / I_{\mathrm{n}}, I_{\text {st }}\right.$ is starting current $)$. If voltage $U_{\mathrm{n}}$, speed $n_{\mathrm{n}}$ and model parameters are given, the other manufacturer indexes can be obtained by induction motor equivalent circuit.

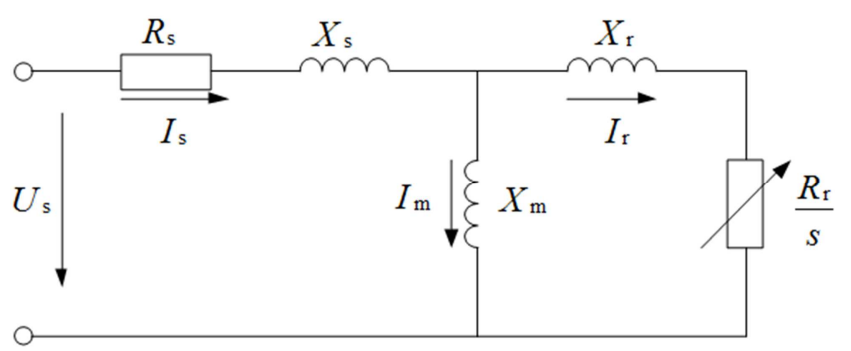

(a) single-cage model

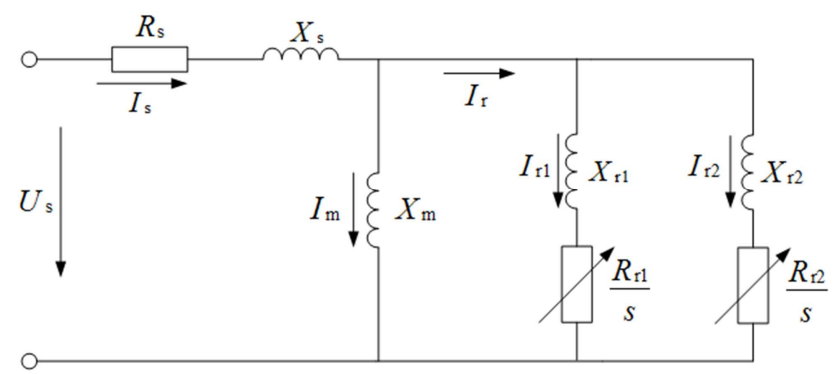

(b) double-cage model

Figure 1. Steady state equivalent circuits for induction motor single-cage and double-cage model.

\section{Identification of Induction Motor Single-Cage Model Parameters}

As show in Figure 1(a), the core loss is ignored in the equivalent circuit of the single-cage model of induction motor. Totally, there are five parameters remained to be identified in the single-cage model, including: $R_{\mathrm{s}}, X_{\mathrm{s}}, X_{\mathrm{m}}, R_{\mathrm{r}}$ and $X_{\mathrm{r}}$. In the manufacturer data, $K_{\text {st }}$ and $K_{\text {Ist }}$ can be used to reflect the starting characteristics of induction motor, but not suitable for the parameter identification of the single-cage model. The input active power of the induction motor is partly consumed by the stator resistance $R_{\mathrm{s}}$, and most of the remaining electric power is transmitted to the rotor through air-gap magnetic field, which is called the electromagnetic power $P_{\mathrm{en}}$. One part of $P_{\mathrm{en}}$ is consumed on the rotor resistance, the rest mechanical 
output power $P_{\mathrm{n}}$ if noise is ignored. Hence, $R_{\mathrm{s}}$ can be first calculated according to paper [8].

$U_{\mathrm{n}}$ and $n_{\mathrm{n}}$ are the basic parameters in induction motor manufacturer data. The input power $P_{1}$ and $Q_{1}$ depend on stator current and power factor, while $K_{\mathrm{m}}$ is an important performance indicator to characterize induction motor overload capacity [15]. Therefore, parameter identifica- tion in this paper is based on these two situations, the first one is that the stator current, the input reactive power and the maximum electromagnetic torque are equal to the corresponding manufacturer data as equality constraints, the second is the relative deviation of the calculation efficiency and the manufacturer data is minimization as the objective function. Taking into account the positive number of the induction motor parameters, a mathematical model for identifying the parameters of $X=\left[X_{\mathrm{s}}, X_{\mathrm{m}}, X_{\mathrm{r}}, R_{\mathrm{r}}\right]$ of the single cage model is established, give the expressions (1) and (2).

$$
\begin{gathered}
\min F(X)=\left(\frac{\eta_{\mathrm{n}}-\eta\left(s_{n}\right)}{\eta_{n}}\right)^{2} \\
\text { s.t. }\left\{\begin{array}{l}
H_{1}(\mathrm{x})=I_{\mathrm{n}}-I_{\mathrm{s}}\left(s_{n}\right)=0 \\
H_{2}(\mathrm{x})=Q_{1}-Q_{1}\left(s_{n}\right)=0 \\
H_{3}(\mathrm{x})=T_{e m}-T_{\mathrm{e}}\left(s_{m}\right)=0 \\
X>0
\end{array}\right.
\end{gathered}
$$

In the formula (2), $\eta_{\mathrm{n}}, I_{\mathrm{n}}, Q_{1}$ and $T_{\mathrm{em}}$ are easy to obtained according to the manufacturer data. $\eta\left(\mathrm{s}_{\mathrm{n}}\right), I_{\mathrm{s}}\left(\mathrm{s}_{\mathrm{n}}\right), Q_{1}\left(\mathrm{~s}_{\mathrm{n}}\right)$ and $T_{\mathrm{e}}\left(\mathrm{s}_{\mathrm{m}}\right)$ can be calculated according to the equivalent circuit parameters identified. The method as follows:

1. The rated slip $s_{\mathrm{n}}$, rated torque $T_{\mathrm{n}}$ and maximum electromagnetic torque $T_{\mathrm{em}}$ of induction motor are calculated as shown in formula (3).

$$
\left\{\begin{array}{l}
s_{n}=\frac{n_{1}-n_{n}}{n_{1}} \\
T_{\mathrm{n}}=\frac{P_{n}}{1-s_{n}} \cdot \frac{1}{\Omega_{\mathrm{s}}} \\
T_{\mathrm{em}}=K_{m} T_{\mathrm{n}}
\end{array}\right.
$$

In formula (3), $n_{1}(\mathrm{r} / \mathrm{min})$ is induction motors synchronous speed, $\Omega_{\mathrm{s}}(\mathrm{rad} / \mathrm{s})$ is induction motors synchronous mechanical angular velocity.

2. The stator impedance and the magnetizing reactance of the single cage model of induction motor is subjected to Thevenin equivalent. The equivalent impedance is:

$$
Z_{\mathrm{th}}=R_{\mathrm{th}}+j X_{\mathrm{th}}=\frac{j X_{\mathrm{m}}\left(R_{\mathrm{s}}+j X_{\mathrm{s}}\right)}{R_{\mathrm{s}}+j\left(X_{\mathrm{s}}+X_{\mathrm{m}}\right)}
$$

3. According to Thevenin equivalent circuit, the critical slip ratio $s_{\mathrm{m}}$ can be computed by

$$
s_{m}=\frac{R_{r}}{\sqrt{R_{t h}^{2}+\left(X_{r}+X_{t h}\right)^{2}}}
$$

4. The equivalent impedance $Z_{\mathrm{m}}(\mathrm{s})$ seen from the side of induction motor stator is computed by

$$
Z_{m}(s)=R_{s}+j X_{s}+\frac{j X_{m} Z_{r}(s)}{j X_{m}+Z_{r}(s)}
$$

In the formula, $Z_{\mathrm{r}}(s)=R_{\mathrm{r}} / s+\mathrm{j} X_{\mathrm{r}}$, is the rotor impedan- ce of induction motor.

5. The stator current $I_{\mathrm{s}}(\mathrm{s})$ and rotor current $I_{\mathrm{r}}(\mathrm{s})$ are given by

$$
\left\{\begin{array}{l}
I_{s} \dot{(s)}=\frac{U_{s}}{Z_{m}(s)} \\
I_{r}(s)=\frac{j X_{m}}{j X_{m}+Z_{r}(s)} I_{s}(s)
\end{array}\right.
$$

6. The electromagnetic torque $T_{\mathrm{e}}(\mathrm{s})$ is computed by

$$
T_{\mathrm{e}}(\mathrm{s})=\frac{1}{\Omega_{\mathrm{s}}} \cdot \frac{3 R_{\mathrm{r}}}{s} \cdot\left|I_{\mathrm{r}}(s)\right|^{2}
$$

According to the single cage model of induction motor, the input active power $P_{1}(\mathrm{~s})$, input reactive power $Q_{1}(\mathrm{~s})$ and output mechanical power $P_{\mathrm{n}}(\mathrm{s})$ are calculated by

$$
\left\{\begin{array}{l}
P_{1}(s)=3 \operatorname{Re} a l\left(U_{\mathrm{s}}\left[I_{\mathrm{s}}(s)\right]^{*}\right) \\
Q_{1}(s)=3 \operatorname{Im}\left(U_{\mathrm{s}}\left[I_{\mathrm{s}}(\dot{s})\right]^{*}\right) \\
P_{\mathrm{n}}(s)=T_{\mathrm{e}}(s) \cdot(1-s) \cdot \Omega_{\mathrm{s}}
\end{array}\right.
$$

The rated slip $s_{\mathrm{n}}$ calculated in equation (3) is substituted into equations (7) and (9) to obtain the stator current $I_{\mathrm{s}}\left(s_{\mathrm{n}}\right)$, the input reactive power $Q_{1}\left(s_{\mathrm{n}}\right)$, and the output mechanical power $P_{\mathrm{n}}\left(s_{\mathrm{n}}\right)$. The critical slip $S_{\mathrm{m}}$ calculated in equation (5) is substituted into equation (8) to obtain the maximum electromagnetic torque $T_{\mathrm{e}}\left(s_{\mathrm{m}}\right)$. The induction motor calculation efficiency is $\eta\left(\mathrm{s}_{\mathrm{n}}\right)=P_{\mathrm{n}}\left(\mathrm{s}_{\mathrm{n}}\right) / P_{1}\left(\mathrm{~s}_{\mathrm{n}}\right)$.

\section{Identification of Induction Motor Double-Cage Model Parameters}

In Figure 1(b), there are seven parameters to be identified in the double-cage model of induction motor. There are 5 independent equations can be listed and written if take the method of solving equations, and two approximate equations need to be added manually (e.g. [13] and [14]), using 
mathematical optimization algorithm will be more advantageous.

According to the analysis of the previous section, the stator current $I_{\mathrm{s}}\left(\mathrm{s}_{\mathrm{n}}\right)$, reactive power $Q_{1}\left(\mathrm{~s}_{\mathrm{n}}\right)$ and maximum electromagnetic torque $T_{\mathrm{e}}\left(\mathrm{s}_{\mathrm{m}}\right)$ calculated by the model are equal to the corresponding manufacturer data is still used as equality constraints. In order to simulate the starting characteristics accurately, this paper adds two equality constraints: calculates the starting torque, starting current equals to the manufacturer data. Similarly, the minimized relative deviation between the computational efficiency of the model and the manufacturer data is still regarded as the objective function. Considering the outer cage resistance is greater than the inner cage resistance while the inner cage reactance is greater than the outer cage reactance [15], and the parameters to be identified must be a positive number, formed the mathematical model of identification parameter $X=\left[X_{\mathrm{s}}, X_{\mathrm{m}}\right.$, $R_{\mathrm{r} 1}, X_{\mathrm{r} 1}, R_{\mathrm{r} 2}, X_{\mathrm{r} 2}$ ] for double cage model, give the expressions such as (10) and (11).

$$
\begin{aligned}
& \min F(X)=\left(\frac{\eta_{\mathrm{n}}-\eta\left(s_{n}\right)}{\eta_{n}}\right)^{2} \\
& \text { s.t. }\left\{\begin{array}{l}
H_{1}(X)=I_{\mathrm{n}}-I_{\mathrm{s}}\left(s_{n}\right)=0 \\
H_{2}(X)=Q_{1}-Q_{1}\left(s_{n}\right)=0 \\
H_{3}(X)=T_{\mathrm{em}}-T_{\mathrm{e}}\left(s_{m}\right)=0 \\
H_{4}(X)=T_{\mathrm{st}}-T_{\mathrm{st}}(1)=0 \\
H_{5}(X)=I_{\mathrm{st}}-I_{\mathrm{st}}(1)=0 \\
R_{\mathrm{r} 2}>R_{\mathrm{r} 1} \\
X_{\mathrm{r} 1}>X_{\mathrm{r} 2} \\
X>0
\end{array}\right.
\end{aligned}
$$

Where, it's easy to obtain $\eta_{\mathrm{n}}, I_{\mathrm{n}}, Q_{1}, T_{\mathrm{em}}, T_{\mathrm{st}}, I_{\mathrm{st}}$ according to the manufacturer data. And $\eta(\mathrm{sn}), I \mathrm{~s}(\mathrm{sn}), Q_{1}(\mathrm{sn}), T_{\mathrm{e}}(\mathrm{sm}), T_{\mathrm{st}}(1)$ and $I_{\mathrm{st}}(1)$ can be calculated according to equivalent circuits. The method as follows:

1. The formula (3) is used to calculate the rated slip $s_{n}$, rated torque $T_{\mathrm{n}}$ and maximum electromagnetic torque $T_{\mathrm{em}}$ of induction motor.

2. Equivalent rotor impedance $Z_{\mathrm{r}}(\mathrm{s})$ of inner and outer -cage impedance $Z_{\mathrm{r} 1}(\mathrm{~s})$ and $Z_{\mathrm{r} 2}(\mathrm{~s})$ in the double-cage model of induction motor is:

$$
Z_{r}(s)=R_{r}+j X_{r}=\frac{Z_{r 1}(s) \cdot Z_{r 2}(s)}{Z_{r 1}(s)+Z_{r 2}(s)}
$$

The expression of $Z_{\mathrm{r} 1}(\mathrm{~s})$ and $Z_{\mathrm{r} 2}(\mathrm{~s})$ is:

$$
\left\{\begin{array}{l}
Z_{r 1}(s)=\frac{R_{r 1}}{s}+j X_{r 1} \\
Z_{r 2}(s)=\frac{R_{r 2}}{s}+j X_{r 2}
\end{array}\right.
$$

3. Then, the stator impedance and the excitation reactance of induction motor double-cage model are subjected to Thevenin equivalent. The equivalent impedance formula is still equation (4), and the critical slip of the double-cage model is still equation (5). From the side of equivalent circuit stator of the double-cage model can be seen, the equivalent impedance $Z_{\mathrm{m}}(\mathrm{s})$ is still equation (6), and the calculation formula of stator current $I_{\mathrm{s}}(\mathrm{s})$ and rotor current $I_{\mathrm{r}}(\mathrm{s})$ is still in equation (7).

4. The formula of inner cage rotor current $I_{\mathrm{r} 1}(s)$ and outer cage rotor current $I_{\mathrm{r} 2}(s)$ is:

$$
\left\{\begin{array}{l}
I_{\mathrm{r} 1}(s)=\frac{Z_{\mathrm{r} 2}(s)}{Z_{\mathrm{r} 1}(s)+Z_{r 2}(s)} I_{r}(s) \\
I_{\mathrm{r} 2}(s)=\frac{Z_{\mathrm{r} 1}(s)}{Z_{\mathrm{r} 1}(s)+Z_{\mathrm{r} 2}(s)} I_{r}(s)
\end{array}\right.
$$

5. The formula of electromagnetic torque $T_{\mathrm{e}}(\mathrm{s})$ is:

$$
T_{\mathrm{e}}(s)=\frac{3}{\Omega_{\mathrm{s}}} \cdot\left(\frac{R_{\mathrm{r} 1}}{s} \cdot\left|I_{\mathrm{r} 1}(s)\right|^{2}+\frac{R_{\mathrm{r} 2}}{s} \cdot\left|I_{\mathrm{r} 2}(s)\right|^{2}\right)
$$

the rated slip $s_{\mathrm{n}}$ calculated in equation (3) substituted into equations (7) and (9), then get the corresponding $s_{\mathrm{n}}$ of stator current $I_{\mathrm{s}}\left(s_{\mathrm{n}}\right)$, input reactive power $Q_{1}\left(s_{\mathrm{n}}\right)$, and output mechanical power $P_{\mathrm{n}}\left(s_{\mathrm{n}}\right)$. Substitute the critical slip $s_{\mathrm{m}}$ and $\mathrm{s}=1$ into equation (15), and the maximum electromagnetic torque $T_{\mathrm{e}}\left(s_{\mathrm{m}}\right)$ and starting torque $T_{\mathrm{st}}(1)$ are obtained. The starting current $I_{\mathrm{st}}(1)$ is obtained by substituting $\mathrm{s}=1$ into the first form of equations (7).

\section{The Basic Principle of Sequential Quadratic Programming Algorithm}

The Sequential Quadratic Programming (SQP) algorithm is widely used in solving nonlinear optimization problems due to its strong nonlinear processing ability and good numerical stability [16], [17]. The basic principle is to determine a downward direction by solving a Sequential Quadratic Programming sub-problem in iteration, get the step size by reducing the cost function, and repeat these steps until the original problem is obtained.

In reference [18], the general mathematical model of SQP algorithm for solving nonlinear constrained optimization problems is described by:

$$
\left\{\begin{array}{lll}
\min & f(\mathrm{x}) \\
\text { s.t. } & h_{i}(x)=0 \quad \mathrm{i} \in \mathrm{E}=\{1,2, \cdots, l\} \\
& g_{i}(x) \geq 0 \quad \mathrm{i} \in \mathrm{I}=\{1,2, \cdots, m\}
\end{array}\right.
$$

In the Formula (16), $x \in R^{n}$ is the decision variable, $f(x)$ is objective function, $h_{i}(x)$ and $g_{i}(x)$ are equality and inequality constraint functions respectively. Construct a Lagrange 
function:

$$
L(x, \mu, \lambda)=f(x)-\sum_{i \in E} \mu_{i} h_{i}(x)-\sum_{i \in I} \lambda_{i} g_{i}(x)
$$

In the formula (17), $\mu$ and $\lambda$ are the Lagrange multiplier vectors for equality constraints and inequality constraints. The constraint function is linearized after fixed points $\left(x_{\mathrm{k}}, \mu_{\mathrm{k}}, \lambda_{\mathrm{k}}\right)$ are given, and the quadratic polynomial approximation of Lagrange function is carried out to obtain the following quadratic programming sub-problems[18], such as formula (18).

$$
\left\{\begin{array}{lll}
\min & \frac{1}{2} d^{T} W_{k} d+\nabla f\left(x_{k}\right)^{T} d & \\
\text { s.t. } & h_{\mathrm{i}}\left(x_{k}\right)+\nabla h_{i}\left(x_{k}\right)^{T} d=0 & i \in E \\
& g_{\mathrm{i}}\left(x_{k}\right)+\nabla g_{i}\left(x_{k}\right)^{T} d \geq 0 & i \in I
\end{array}\right.
$$

In formula (18), $W_{\mathrm{k}}=W\left(x_{\mathrm{k}}, \mu_{k}, \lambda_{k}\right)=\nabla L_{x x}=\left(x_{\mathrm{k}}, \mu_{k}, \lambda_{k}\right), \nabla f\left(x_{\mathrm{k}}\right)$ is a gradient of $f\left(x_{\mathrm{k}}\right)$ at $x_{\mathrm{k}} . \nabla h_{\mathrm{i}}\left(x_{\mathrm{k}}\right)$ and $\nabla g_{\mathrm{i}}\left(x_{\mathrm{k}}\right)$ is a gradient of $h_{\mathrm{i}}\left(x_{\mathrm{k}}\right)$ and $g_{\mathrm{i}}\left(x_{\mathrm{k}}\right)$ at $x_{\mathrm{k}}$.

The optimal solution $d^{*}$ of formula (18) can be used as the direction of search for the variable $x$ of the original problem in the $k$ iteration process.

The real Hessian matrix $W_{\mathrm{k}}$ of the second derivative of Lagrange function is:

$$
W_{k}=\nabla^{2} f\left(x_{k}\right)-\sum_{i=1}^{1} \mu_{i} \nabla^{2} h_{i}\left(x_{k}\right)-\sum_{i=1}^{\mathrm{m}} \lambda_{i} \nabla^{2} g_{i}\left(x_{k}\right)
$$

Because of the computation of $W_{\mathrm{k}}$ is very cumbersome, Mathematician proposed a sequential quadratic programming method using symmetric positive definite matrix $B_{\mathrm{k}}$ instead of $W_{\mathrm{k}}$, and the obtainment of $B_{\mathrm{k}}$ can be referred in [18]. In order to ensure global convergence of the solution results, SQP algorithm also uses a cost function to determine the step size $\alpha_{\mathrm{k}}$ of searching along the search direction of $d_{\mathrm{k}}$ [18]. After obtaining the search step size, the SQP algorithm obtains the next iteration point $x_{\mathrm{k}+1}$ through the formula (20).

$$
x_{k+1}=x_{k}+\alpha_{k} d_{k}^{*}
$$

Lagrange multiplier updates as in equation (21). SQP algorithm is used to solve constraint optimization problem as shown in Figure 2.

$$
\left\{\begin{array}{l}
A_{k+1}=\left[\begin{array}{l}
\nabla h\left(x_{k+1}\right)^{T} \\
\nabla g\left(x_{k+1}\right)^{T}
\end{array}\right] \\
{\left[\begin{array}{c}
\mu_{k+1} \\
\lambda_{k+1}
\end{array}\right]=\left[A_{k+1} A_{k+1}^{T}\right]^{-1} A_{k+1} \nabla f_{k+1}}
\end{array}\right.
$$

When identifying the single cage model parameters $X=[X \mathrm{~s}$, $\left.X_{\mathrm{m}}, R_{\mathrm{r}}, X_{\mathrm{r}}\right]$ of induction motor, the initial value of variable $\mathrm{X}$ as in equation (22) [13].

$$
\left\{\begin{array}{l}
R_{\mathrm{r}}=\frac{3 U_{\mathrm{s}}^{2}}{P_{\mathrm{n}}} \cdot s_{\mathrm{n}} \\
X_{\mathrm{m}}=\frac{3 U_{\mathrm{s}}^{2}}{Q_{1}} \\
X_{\mathrm{s}}=0.05 X_{\mathrm{m}} \\
X_{\mathrm{r}}=X_{\mathrm{s}}
\end{array}\right.
$$

When identifying the double cage model para- meters $X=\left[X \mathrm{~s}, X \mathrm{~m}, R_{\mathrm{r} 1}, X_{\mathrm{r} 1}, R_{\mathrm{r} 2}, X_{\mathrm{r} 2}\right]$ of induction motor, the initial value of $R_{\mathrm{r} 1}, X_{\mathrm{m}}, X_{\mathrm{s}}$ and $X_{\mathrm{r}}$ are the same as in single-cage model $\left(R_{\mathrm{r}}, X_{\mathrm{m}}, X_{\mathrm{s}}\right.$ and $\left.X_{\mathrm{r}}\right)$, the initial value of $R_{\mathrm{r} 2}, X_{\mathrm{r} 1}, X_{\mathrm{r} 2}$ are computed by equation (23) [13].

$$
\left\{\begin{array}{l}
R_{\mathrm{r} 2}=2 R_{\mathrm{r} 1} \\
X_{\mathrm{r} 1}=2 X_{\mathrm{s}} \\
X_{\mathrm{r} 2}=X_{\mathrm{s}}
\end{array}\right.
$$

After the induction motor load model parameters are identified, the nominal value of the parameter is calculated as the standard value with the rated voltage $U_{\mathrm{n}}$ and the rated mechanical power $P_{\mathrm{n}}$ as the reference values. According to equation (24), the induction motor inertia time constant $T_{\mathrm{j}}$ is obtained [15].

$$
T_{\mathrm{j}}=\frac{J \Omega_{\mathrm{s}}^{2}}{P_{\mathrm{n}}}
$$

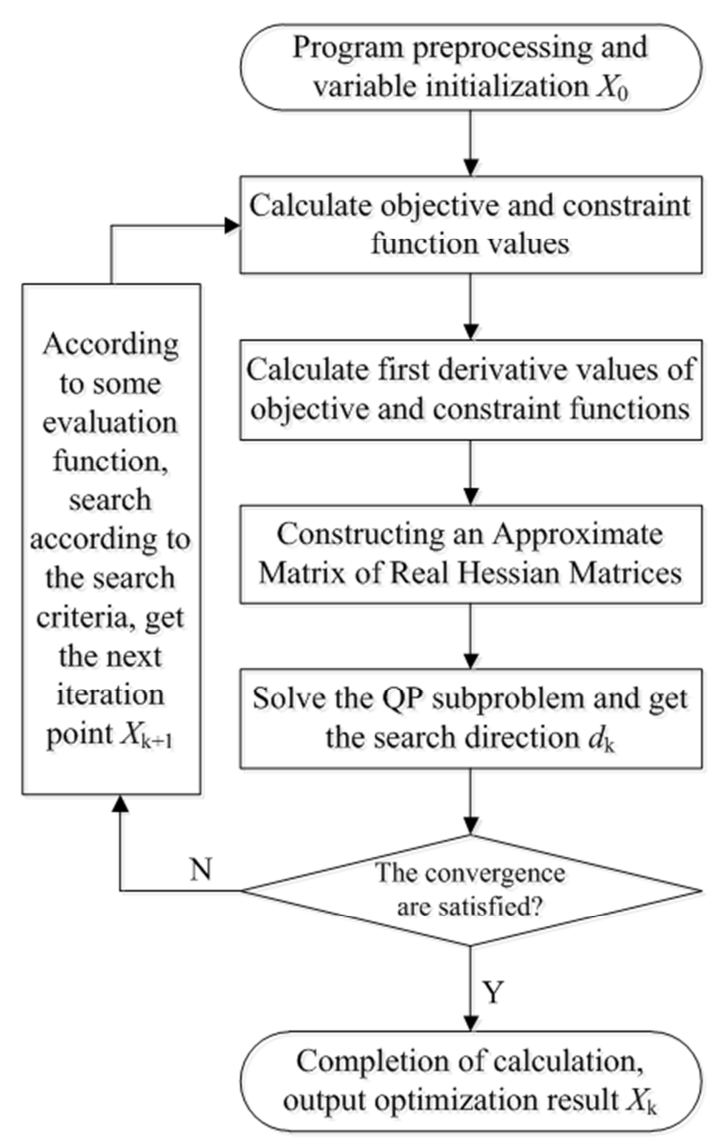

Figure 2. SQP Algorithm Flow Chart. 


\section{Model and Algorithm Validation}

Table 1 are shows the manufacturer data of 6 induction motors. By using the proposed identification model and algorithm, the parameters of each induction motor's single-cage model and double-cage model are calculated as shown in Table 2 and Table 3.

According to the model parameters in Table 2 and Table 3, the performance indexes of induction motor are calculated. The comparison between the calculated performance index and the manufacturer data is shown in Table 4 and Table 5. It can be seen that the single cage model can reflect the working characteristics of induction motor accurately except the starting performance. The calculated performance indexes of the double cage model are consistent with the manufacturer data.

Table 1. Manufacturer data of induction motors.

\begin{tabular}{|c|c|c|c|c|c|c|c|c|c|c|c|}
\hline No. & $P_{\mathrm{n}} / \mathbf{k W}$ & $U_{\mathrm{n}} / \mathbf{k V}$ & $I_{\mathrm{n}} / \mathbf{A}$ & $n(\mathbf{r} / \mathrm{min})$ & $\eta_{\mathrm{n}} / \%$ & $\cos \theta_{n}$ & $K_{\mathrm{m}}$ & $K_{\text {st }}$ & $K_{\text {Ist }}$ & $J / \mathrm{kg} \cdot \mathrm{m}^{2}$ & $\mathbf{P}$ \\
\hline M1 & 1400 & 10.0 & 95.0 & 1492 & 95.9 & 0.890 & 2.38 & 0.85 & 6.43 & 510.0 & 2 \\
\hline M2 & 1250 & 10.0 & 85.0 & 1492 & 95.9 & 0.890 & 2.29 & 0.86 & 6.04 & 455.5 & 2 \\
\hline M3 & 850 & 6.0 & 96.8 & 1488 & 95.2 & 0.894 & 2.47 & 1.49 & 6.00 & 214.0 & 2 \\
\hline M4 & 680 & 6.0 & 78.0 & 1488 & 94.7 & 0.890 & 2.40 & 1.30 & 5.68 & 173.0 & 2 \\
\hline M5 & 200 & 0.38 & 347.0 & 2975 & 94.8 & 0.925 & 2.50 & 2.20 & 7.20 & 8.00 & 1 \\
\hline M6 & 110 & 0.38 & 191.0 & 2977 & 95.8 & 0.900 & 3.10 & 2.40 & 8.30 & 3.190 & 1 \\
\hline
\end{tabular}

Table 2. Calculated parameters of induction motor single-cage model.

\begin{tabular}{lllllll}
\hline $\boldsymbol{P}_{\mathbf{n}} / \mathbf{k W}$ & $\boldsymbol{R}_{\mathbf{s}} / \mathbf{p u}$ & $\boldsymbol{X}_{\mathbf{s}} / \mathbf{p u}$ & $\boldsymbol{R}_{\mathbf{r}} / \mathbf{p u}$ & $\boldsymbol{X}_{\mathbf{r}} / \mathbf{p u}$ & $\boldsymbol{X}_{\mathbf{m}} / \mathbf{p u}$ \\
\hline 1400 & 0.0294 & 0.1411 & 0.0043 & 0.0253 & 2.6353 \\
1250 & 0.0309 & 0.1315 & 0.0043 & 0.0413 & 2.6992 \\
850 & 0.0357 & 0.1179 & 0.0065 & 0.0341 & 2.5421 \\
680 & 0.0372 & 0.1222 & 0.0064 & 0.0332 & 2.4717 \\
200 & 0.0346 & 0.0755 & 0.0071 & 0.0792 & 3.6072 \\
110 & 0.0159 & 0.0659 & 0.0069 & 0.0721 & 2.1096 \\
\hline
\end{tabular}

Table 3. Calculated parameters of induction motor double-cage model.

\begin{tabular}{lllllll}
\hline $\boldsymbol{P}_{\mathbf{n}} / \mathbf{k w}$ & $\boldsymbol{R}_{\mathbf{s}} / \mathbf{p u}$ & $\boldsymbol{X}_{\mathbf{s}} / \mathbf{p u}$ & $\boldsymbol{R}_{\mathbf{r} 1} / \mathbf{p u}$ & $\boldsymbol{X}_{\mathbf{r} 1} / \mathbf{p u}$ & $\boldsymbol{R}_{\mathbf{r} 2} / \mathbf{p u}$ & $\boldsymbol{X}_{\mathbf{r} 2} / \mathbf{p u}$ \\
\hline 1400 & 0.0763 & 0.0403 & 0.0046 & 0.0638 & 0.2833 & 0.0574 \\
1250 & 0.0271 & 0.1122 & 0.0052 & 0.0926 & 0.0278 & 0.0216 \\
850 & 0.0305 & 0.0863 & 0.0073 & 0.0870 & 0.0814 & 0.0319 \\
680 & 0.0339 & 0.0875 & 0.0071 & 0.0841 & 0.0997 & 0.0396 \\
200 & 0.0358 & 0.0679 & 0.0081 & 0.1111 & 0.0589 & 0.0239 \\
110 & 0.0272 & 0.0196 & 0.0074 & 0.1206 & 0.1345 & 0.1191 \\
\hline
\end{tabular}

Table 4. Comparison of the calculated and manufacturer performance indexes for induction motor single-cage model.

\begin{tabular}{|c|c|c|c|c|c|c|}
\hline \multirow{2}{*}{ Indexes } & \multicolumn{2}{|l|}{$1400 \mathrm{~kW} 1250$} & \multicolumn{2}{|l|}{$1250 \mathrm{~kW}$} & \multicolumn{2}{|l|}{$850 \mathrm{~kW}$} \\
\hline & Manufacturer & Calculated & Manufacturer & Calculated & Manufacturer & Calculated \\
\hline$P_{1}(\mathrm{~kW})$ & 1464.45 & 1463.55 & 1310.29 & 1312.45 & 899.34 & 899.47 \\
\hline$Q_{1}(\mathrm{kVar})$ & 750.26 & 749.95 & 671.285 & 672.13 & 450.75 & 450.77 \\
\hline$I_{\mathrm{n}}(\mathrm{A})$ & 95.0 & 94.95 & 85.0 & 85.13 & 96.8 & 96.81 \\
\hline$P_{\mathrm{n}}(\mathrm{kW})$ & 1400 & 1399.30 & 1250 & 1252.03 & 850 & 850.1 \\
\hline $\cos \theta_{n}$ & 0.89 & 0.89 & 0.89 & 0.8901 & 0.894 & 0.894 \\
\hline$\eta_{\mathrm{n}}(\%)$ & 0.959 & 0.9561 & 0.959 & 0.9540 & 0.952 & 0.9451 \\
\hline$K_{\mathrm{st}}$ & 0.85 & 0.15 & 0.86 & 0.1344 & 1.49 & 0.2538 \\
\hline$K_{\text {Ist }}$ & 6.43 & 5.02 & 6.04 & 4.8318 & 6.00 & 5.372 \\
\hline
\end{tabular}

Table 4. Continued

\begin{tabular}{|c|c|c|c|c|c|c|}
\hline \multirow{2}{*}{ Indexes } & \multicolumn{2}{|l|}{$680 \mathrm{~kW}$} & \multicolumn{2}{|l|}{$200 \mathrm{~kW}$} & \multicolumn{2}{|l|}{$110 \mathrm{~kW}$} \\
\hline & Manufacturer & Calculated & Manufacturer & Calculated & Manufacturer & Calculated \\
\hline$P_{1}(\mathrm{~kW})$ & 721.43 & 724.3 & 210.65 & 210.82 & 113.14 & 112.99 \\
\hline$Q_{1}(\mathrm{kVar})$ & 369.602 & 370.62 & 86.53 & 86.56 & 54.8 & 54.75 \\
\hline$I_{\mathrm{n}}(\mathrm{A})$ & 78.0 & 78.29 & 346.0 & 346.26 & 191.0 & 190.76 \\
\hline$P_{\mathrm{n}}(\mathrm{kW})$ & 680 & 682.58 & 200 & 200.16 & 110 & 109.86 \\
\hline $\cos \theta n$ & 0.89 & 0.8902 & 0.925 & 0.925 & 0.9 & 0.8999 \\
\hline$\eta_{\mathrm{n}}(\%)$ & 0.947 & 0.9424 & 0.948 & 0.9494 & 0.958 & 0.9723 \\
\hline$K_{\mathrm{m}}$ & 2.40 & 2.3995 & 2.50 & 2.5009 & 3.1 & 3.1016 \\
\hline$K_{\mathrm{st}}$ & 1.30 & 0.2386 & 2.20 & 0.2683 & 2.4 & 0.3413 \\
\hline$K_{\text {Ist }}$ & 5.68 & 5.2122 & 7.20 & 5.5405 & 8.3 & 6.3403 \\
\hline
\end{tabular}


Table 5. Comparison of the calculated and manufacturer performance indexes for induction motor double-cage model.

\begin{tabular}{|c|c|c|c|c|c|c|}
\hline \multirow{2}{*}{ Indexes } & \multicolumn{2}{|l|}{$1400 \mathrm{~kW}$} & \multicolumn{2}{|l|}{$1250 \mathrm{~kW}$} & \multicolumn{2}{|l|}{850 kW } \\
\hline & Manufacturer & Calculated & Manufacturer & Calculated & Manufacturer & Calculated \\
\hline$P_{1}(\mathrm{~kW})$ & 1464.45 & 1464.19 & 1310.29 & 1309.64 & 899.34 & 897.75 \\
\hline$Q_{1}(\mathrm{kVar})$ & 750.25 & 750.27 & 671.285 & 671.27 & 450.75 & 450.16 \\
\hline$I_{\mathrm{n}}(\mathrm{A})$ & 95.00 & 94.99 & 85.00 & 84.97 & 96.8 & 96.64 \\
\hline$P_{\mathrm{n}}(\mathrm{kW})$ & 1400 & 1405.77 & 1250 & 1255.99 & 850 & 854.66 \\
\hline $\cos \theta \mathrm{n}$ & 0.890 & 0.890 & 0.890 & 0.8899 & 0.894 & 0.8939 \\
\hline$\eta_{\mathrm{n}}(\%)$ & 0.959 & 0.9601 & 0.959 & 0.9590 & 0.952 & 0.9520 \\
\hline$K_{\mathrm{m}}$ & 2.38 & 2.3799 & 2.29 & 2.2889 & 2.47 & 2.4693 \\
\hline$K_{\mathrm{st}}$ & 0.85 & 0.8484 & 0.86 & 0.8619 & 1.49 & 1.4903 \\
\hline$K_{\text {Ist }}$ & 6.43 & 6.4299 & 6.04 & 6.0408 & 6.00 & 5.9993 \\
\hline
\end{tabular}

Table 5. Continued.

\begin{tabular}{|c|c|c|c|c|c|c|}
\hline \multirow{2}{*}{ Indexes } & \multicolumn{2}{|l|}{$680 \mathrm{~kW}$} & \multicolumn{2}{|l|}{$200 \mathrm{~kW}$} & \multicolumn{2}{|l|}{$110 \mathrm{~kW}$} \\
\hline & Manufacturer & Calculated & Manufacturer & Calculated & Manufacturer & Calculated \\
\hline$P_{1}(\mathrm{~kW})$ & 721.438 & 720.95 & 210.65 & 210.62 & 113.14 & 113.258 \\
\hline$Q_{1}(\mathrm{kVar})$ & 369.60 & 369.38 & 86.53 & 86.525 & 54.80 & 54.66 \\
\hline$I_{\mathrm{n}}(\mathrm{A})$ & 78.00 & 77.95 & 346.00 & 345.95 & 191.00 & 191.07 \\
\hline$P_{\mathrm{n}}(\mathrm{kW})$ & 680 & 682.72 & 200 & 199.67 & 110 & 108.48 \\
\hline $\cos \theta$ n & 0.890 & 0.890 & 0.925 & 0.925 & 0.900 & 0.9006 \\
\hline$K_{\mathrm{m}}$ & 2.40 & 2.4000 & 2.50 & 2.4992 & 3.10 & 3.1001 \\
\hline$K_{\mathrm{st}}$ & 1.30 & 1.3009 & 2.20 & 2.1998 & 2.40 & 2.4024 \\
\hline$K_{\text {Ist }}$ & 5.68 & 5.6801 & 7.20 & 7.1994 & 8.30 & 8.3024 \\
\hline
\end{tabular}

Table 6. Comparison of single-cage model parameters of induction motor.

\begin{tabular}{|c|c|c|c|c|c|c|}
\hline IM Capacity & Calculation Method & $R_{\mathrm{s}} / \mathbf{p u}$ & $X_{\mathrm{s}} / \mathbf{p u}$ & $\boldsymbol{R}_{\mathrm{r}} / \mathbf{p u}$ & $X_{\mathbf{r}} / \mathbf{p u}$ & $X_{\mathrm{m}} / \mathbf{p u}$ \\
\hline \multirow{3}{*}{$1400 \mathrm{~kW}$} & Method 1 & 0.0294 & 0.1411 & 0.0043 & 0.0253 & 2.6353 \\
\hline & Method 2 & 0.0294 & 0.0844 & 0.0045 & 0.0844 & 2.6920 \\
\hline & Method 3 & 0.0069 & 0.1273 & 0.0046 & 0.0636 & 2.9610 \\
\hline \multirow{3}{*}{$1250 \mathrm{~kW}$} & Method 1 & 0.0309 & 0.1315 & 0.0043 & 0.0413 & 2.6992 \\
\hline & Method 2 & 0.0309 & 0.0874 & 0.0045 & 0.0874 & 2.7432 \\
\hline & Method 3 & 0.0069 & 0.1324 & 0.0046 & 0.0662 & 3.0419 \\
\hline
\end{tabular}

The methods proposed in this paper, paper [8] and [13] are method 1, method 2 and method 3 respectively, Taking $1400 \mathrm{~kW}$ and $1250 \mathrm{~kW}$ induction motors as an example. The comparison of single cage model parameters calculated by the three methods is shown in Table 6, and the comparison of performance indexes is shown in Table 7.

The induction motor torque-slip characteristic calculated from the parameters identified by three methods is shown in Figure 3 and Figure 4 respectively.

Table 7. Comparison of the calculated and manufacturer performance indexes for motor single-cage model.

\begin{tabular}{|c|c|c|c|c|c|}
\hline IM Capacity & Indexes & Manufa-cturer & Method 1 Calculate & Method 2 Calculate & Method 3 Calculate \\
\hline \multirow{7}{*}{$1400 \mathrm{~kW}$} & $P_{1}(\mathrm{~kW})$ & 1464.45 & 1463.55 & 1459.69 & 1410.85 \\
\hline & $Q_{1}(\mathrm{kVar})$ & 750.26 & 749.95 & 748.66 & 746.15 \\
\hline & $I_{\mathrm{n}}(\mathrm{A})$ & 95.0 & 94.95 & 94.71 & 92.15 \\
\hline & $P_{\mathrm{n}}(\mathrm{kW})$ & 1400 & 1399.3 & 1395.74 & 1390.88 \\
\hline & $\cos \theta n$ & 0.89 & 0.89 & 0.8898 & 0.884 \\
\hline & $\eta_{\mathrm{n}}(\%)$ & 0.959 & 0.9561 & 0.9562 & 0.9858 \\
\hline & $K_{\mathrm{m}}$ & 2.38 & 2.3809 & 2.3799 & 2.3797 \\
\hline \multirow{7}{*}{$1250 \mathrm{~kW}$} & $P_{1}(\mathrm{~kW})$ & 1310.29 & 1312.45 & 1297.26 & 1253.97 \\
\hline & $Q_{1}(\mathrm{kVar})$ & 671.285 & 672.13 & 666.15 & 664.84 \\
\hline & $I_{\mathrm{n}}(\mathrm{A})$ & 85.0 & 85.13 & 84.19 & 81.99 \\
\hline & $P_{\mathrm{n}}(\mathrm{kW})$ & 1250 & 1252.03 & 1238.09 & 1236.26 \\
\hline & $\cos \theta n$ & 0.89 & 0.8901 & 0.8896 & 0.8835 \\
\hline & $\eta_{\mathrm{n}}(\%)$ & 0.959 & 0.9540 & 0.9544 & 0.9859 \\
\hline & $K_{\mathrm{m}}$ & 2.29 & 2.2902 & 2.2911 & 2.289 \\
\hline
\end{tabular}




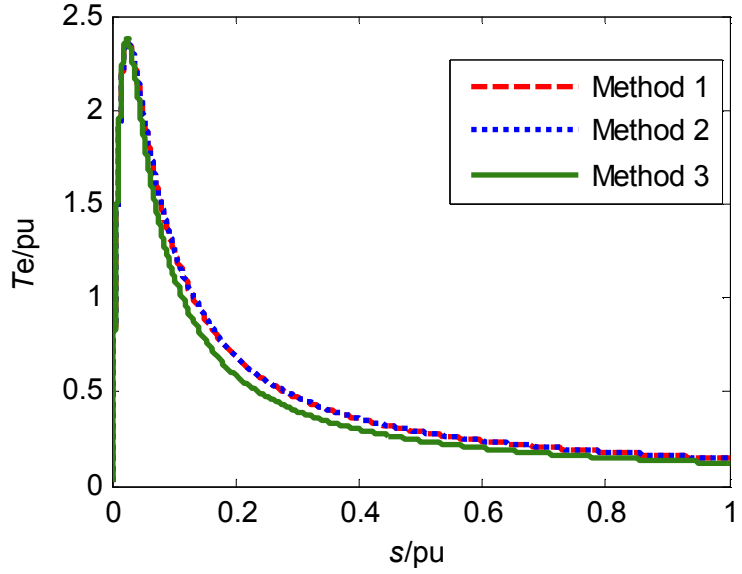

Figure 3. Comparison torque-slip curves for $1400 \mathrm{~kW}$ induction motor single-cage model.

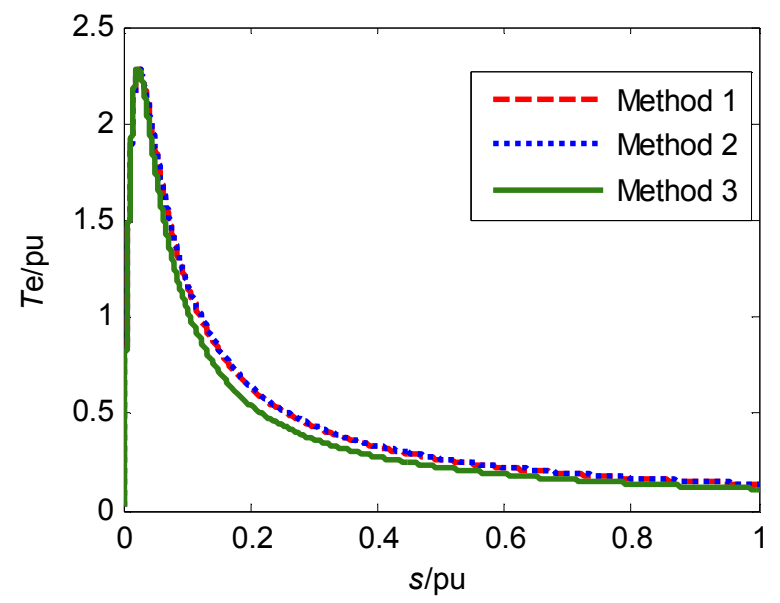

Figure 4. Comparison torque-slip curves for $1250 \mathrm{~kW}$ induction motor single-cage model.

The parameters of double cage model calculated by method 1 and 3 are shown in Table 8, and the comparison of performance indexes is shown in Table 9. The induction motor electromagnetic torque-slip curve and current-slip characteristic curve are calculated according to the parameters of the double-cage model identified by method 1 and method 3 is shown in Figure 5 to Figure 8 . It can be seen that the performance indexes obtained in this paper is closer to the manufacturer data.

Table 8. Comparison of induction motor double-cage model parameters.

\begin{tabular}{lllll}
\hline \multirow{2}{*}{ IM Parameters } & $\mathbf{1 4 0 0 k W}$ & \multicolumn{3}{c}{ 1250kW } \\
\cline { 2 - 5 } & Method 1 & Method 3 & Method 1 & Method 3 \\
\hline$R_{\mathrm{s}} / \mathrm{pu}$ & 0.0763 & 0.0079 & 0.0271 & 0.0076 \\
$X_{\mathrm{s}} / \mathrm{pu}$ & 0.0403 & 0.0911 & 0.1122 & 0.0970 \\
$R_{\mathrm{r} 1} / \mathrm{pu}$ & 0.0046 & 0.0053 & 0.0052 & 0.0051 \\
$X_{\mathrm{r} 1} / \mathrm{pu}$ & 0.0638 & 0.1543 & 0.0926 & 0.1528 \\
$R_{\mathrm{r} 2} / \mathrm{pu}$ & 0.2833 & 0.0365 & 0.0278 & 0.0439 \\
$X_{\mathrm{r} 2} / \mathrm{pu}$ & 0.0574 & 0.0456 & 0.0216 & 0.0485 \\
$X_{\mathrm{m}} / \mathrm{pu}$ & 2.9589 & 2.7383 & 2.7980 & 2.8201 \\
\hline
\end{tabular}

Table 9. Comparison of the calculated and manufacturer performance indexes for motor double-cage model.

\begin{tabular}{|c|c|c|c|c|}
\hline $\begin{array}{l}\text { IM } \\
\text { Capacity }\end{array}$ & Indexes & Manufacturer & $\begin{array}{l}\text { Method } 1 \\
\text { Calculate }\end{array}$ & $\begin{array}{l}\text { Method } 3 \\
\text { Calculate }\end{array}$ \\
\hline \multirow{9}{*}{$1400 \mathrm{~kW}$} & $P_{1}(\mathrm{~kW})$ & 1464.45 & 1464.19 & 1411.63 \\
\hline & $Q_{1}(\mathrm{kVar})$ & 750.26 & 750.27 & 816.45 \\
\hline & $I_{\mathrm{n}}(\mathrm{A})$ & 95.0 & 94.99 & 94.15 \\
\hline & $P_{\mathrm{n}}(\mathrm{kW})$ & 1400.0 & 1405.27 & 1389.22 \\
\hline & $\cos \theta n$ & 0.89 & 0.89 & 0.8656 \\
\hline & $\eta_{\mathrm{n}}(\%)$ & 0.959 & 0.9601 & 0.9845 \\
\hline & $K_{\mathrm{m}}$ & 2.38 & 2.3799 & 2.1834 \\
\hline & $K_{\text {st }}$ & 0.85 & 0.8484 & 1.1726 \\
\hline & $K_{\mathrm{Ist}}$ & 6.43 & 6.4299 & 6.4201 \\
\hline \multirow{9}{*}{$1250 \mathrm{~kW}$} & $P_{1}(\mathrm{~kW})$ & 1310.29 & 1309.64 & 1265.55 \\
\hline & $Q_{1}(\mathrm{kVar})$ & 671.285 & 671.27 & 736.3948 \\
\hline & $I_{\mathrm{n}}(\mathrm{A})$ & 85.0 & 84.97 & 84.5359 \\
\hline & $P_{\mathrm{n}}(\mathrm{kW})$ & 1250 & 1255.99 & 1245.88 \\
\hline & $\cos \theta \mathrm{n}$ & 0.89 & 0.8899 & 0.8643 \\
\hline & $\eta_{\mathrm{n}}(\%)$ & 0.959 & 0.9590 & 0.9845 \\
\hline & $K_{\mathrm{m}}$ & 2.29 & 2.2889 & 2.0782 \\
\hline & $K_{\text {st }}$ & 0.86 & 0.8619 & 1.1726 \\
\hline & $K_{\text {Ist }}$ & 6.04 & 6.0408 & 5.9901 \\
\hline
\end{tabular}

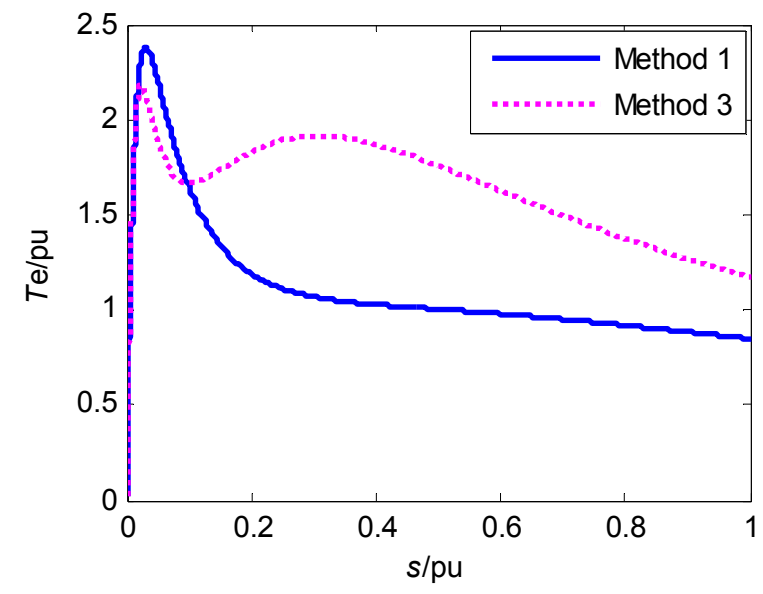

Figure 5. Comparison torque-slip curves for $1400 \mathrm{~kW}$ induction motor double-cage model.

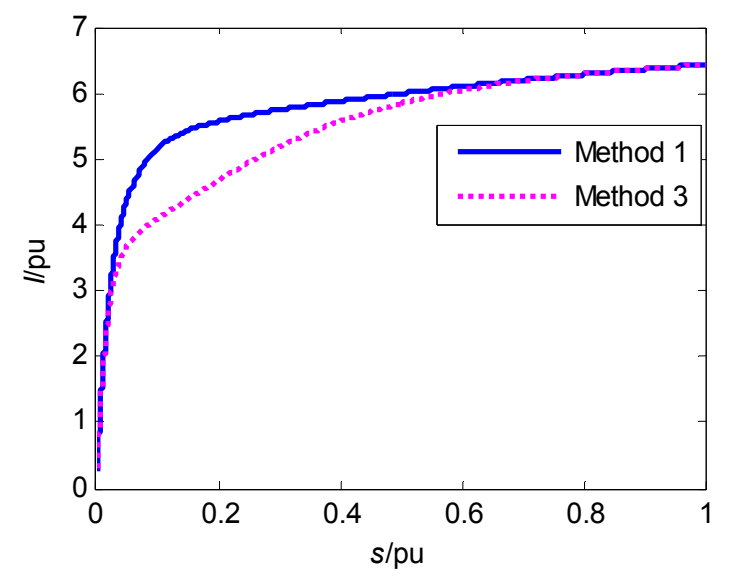

Figure 6. Comparison current-slip curves for $1400 \mathrm{~kW}$ induction motor double-cage model. 


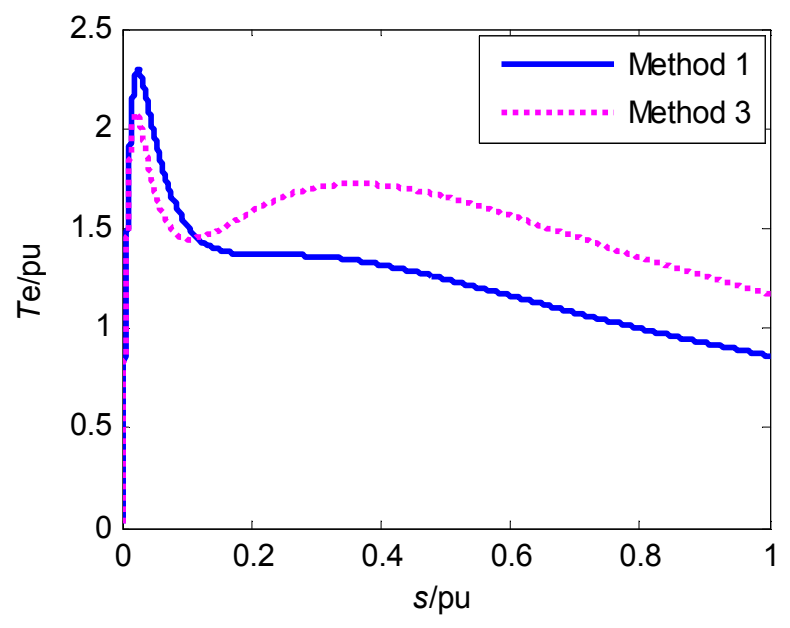

Figure 7. Comparison torque-slip curves for $1250 \mathrm{~kW}$ induction motor double-cage model.

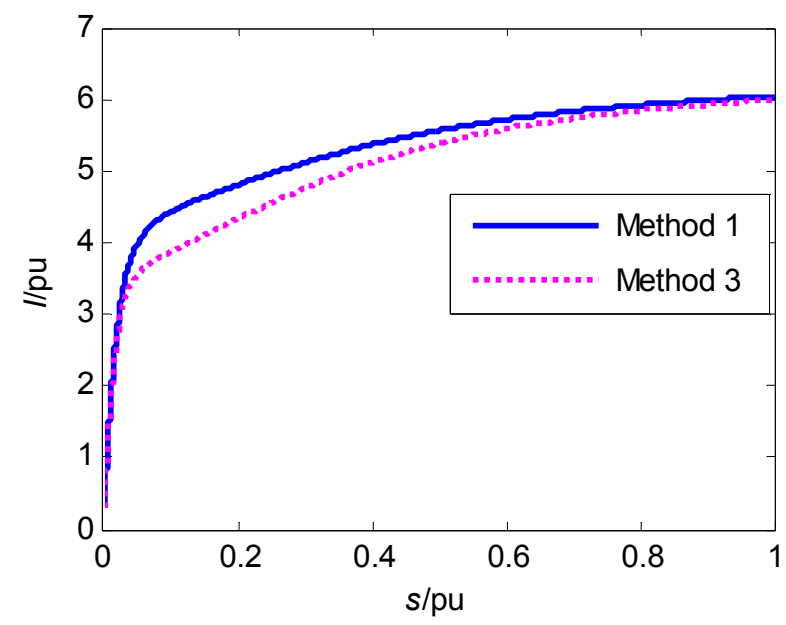

Figure 8. Comparison current-slip curves for $1250 \mathrm{~kW}$ induction motor double-cage model.

\section{Conclusion}

In the parameters identification of induction motor model, it is often considered that the stator parameters are proportional to the rotor parameters, which will cause some errors.

In this paper, a new optimization model for parameters identification of induction motor model based on the manufacturer data is proposed, the model is aimed at calculating the minimum efficiency deviation, using the induction motor stator current, the input reactive power, the maximum electromagnetic torque and the starting parameters are equal to the manufacturer value as constraint conditions, adopting Sequential Quadratic Programming (SQP) algorithm to solve nonlinear model.

The proposed mathematical model and algorithm were tested on a sample of 6 induction motors of different capacity, manufacturers, and rated voltage. The induction motor performance characteristics supplied by the manufacturer and used to identification parameters of induction motor are then calculated, using the equivalent circuit estimated parameters themselves. In all the studied cases, the calculated induction motors performance indexes are found to be in excellent agreement with the manufacturer data. Comparison with other methods shows that the induction motor model parameters obtained by this method can reflect the working characteristics of induction motors more accurately.

\section{Funding}

The authors wish to thank the editors and the anonymous reviewers for their valuable suggestions and critical comments to improve the paper. The research work in this paper was financially supported by the Natural Science Foundation of Guangdong Province (Project No. 2014A030313509; S2013010012431), Thanks!

\section{References}

[1] GU Zhuoyuan, TANG Yong, YI Jun, et al. Study on Mechanism of Interrelationship Between Power System Angle Stability and Induction Motor Stability [J], Power System Technology, 2017, 41(12): 2499-2505.

[2] XIE Haipeng, HE Jian, BIE Zhaohong, et al., Reliability Evaluation of Large-scale Hybrid AC/DC Grids Based on SOCP Load Shedding Model [J], Power System Technology, 2016, 40(12): 3761-3767.

[3] J. Modarresi, E. Gholipour, A. Khodabakhshian, "A comprehensive review of the voltage stability indices," Renewable and Sustainable Energy Reviews, vol. 63, pp. 1-12, Sep, 2016.

[4] H. Y. Yuan, F. X. Li, Hybrid voltage stability assessment (VSA) for N-1 contingency, Electric Power Systems Research, vol. 122, pp. 65-75, May. 2015.

[5] Zhou Qinyong, Zhang Yantao, He Hailei, et al. A practical site selection method for dynamic reactive power compensation in multi-infeed DC power grid [J]. Power System Technology, 2014, 38(7): 1753-1757.

[6] Tang Yong, Zhang Hongbin, Hou Junxian, et al. Study on essential principle and methods for load modeling [J]. Power System Technology, 2007, 31(4): 1-5.

[7] Li Peng, Yu Yixin, Jia Hongjie. A study on models and methods for identifying of voltage stability limit more precisely $[\mathrm{J}]$. Proceedings of the CSEE, 2004, 24(10): 21-26.

[8] Zhao Bing, Tang Yong, Zhang Wenchao, et al. Determination of induction motor simulation model parameters based on the motor manufacturer Data [J]. Power System Technology, 2010, 30(1): 52-58.

[9] Rogers G. J, Shirmohammadi D., Induction machine modeling for electromagnetic transient program [J]. IEEE Trans. On Energy Conversion, 1987, 2(4): 622-628.

[10] Abdelaziz M. M. A, El-Saadany E. F. Estimation of Induction Motor Single-Cage Model Parameters from Manufacturer Data [J]. 2013 IEEE Power and Energy Society General Meeting, 2013: $1-5$

[11] Sakthivel V. P, Bhuvaneswari R, Subramanian S. Multiobjective parameter estimation of induction motor using particle swarm optimization [J]. Engineering Applications of Artificial Intelligence, 2010, 23: 302-312. 
[12] ABRO A. G, Saleh J. M. Multiple-global-best guided artificial bee colony algorithm for induction motor parameter estimation [J]. IEEE Trans. On Energy Conversion, 2014, 22:620-636.

[13] Pedra J, Corcoles F. Estimation of induction motor double-cage model parameters from manufacturer data [J]. IEEE Trans. On Energy Conversion, 2004, 19(2): 310-316.

[14] Pedra J, Corcoles F. On the Determination of Induction Motor Parameters From Manufacturer Data for electro- magnetic transient programs [J]. IEEE Trans. On Energy Conversion, 2008, 23(4): 1709-1718.

[15] Tang Yunqiu, Luo yingli, Liang Yanping. Electrical Machinery [M]. Beijing: China Machine Press, 2008.

[16] Philip E. GILL. User's Guide for SNOPT Version 7: Software for Large-Scale Nonlinear Programming, 2008.

[17] Jiang Aipeng. Large scale reduced space SQP algorithm and its application in process system optimization [D]. Hangzhou: Zhejianguniversity, 2008.

[18] Ma Changfeng. Optimization method and its MATLAB program esign [M]. Beijing: Science Press, 2010: 211-251.

[19] China Electric Power Science Research Institute, PSD-BPA Transient stability program user manual, Chinese Version 4.15.

\section{Biography}

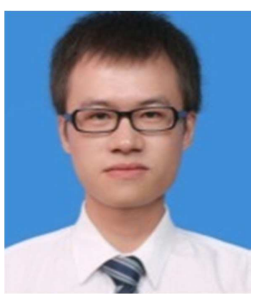

Weiping Liao received his M.S. degree in Guangdong University of Technology, Guangzhou, China, in 2016. He is now an engineer in Jiangmen Power Supply Bureau, Guangdong Power Grid Co., Ltd. His major field of interest is power system voltage stability and load modeling, distribution network automation technology.

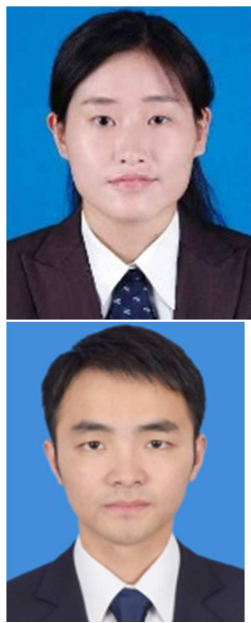

Yan Zhang received her M.S. degree in Guangdong University of Technology, Guangzhou, China, in 2008. She is now an engineer in Jiangmen Power Supply Bureau, Guangdong Power Grid Co., Ltd. Her major field of interest is smart grid planning and construction, distribu tion network automation construction.

Rui Zhou received his B.S. degree in NorthEast Electric Power University, Jilin, China, in 2015. $\mathrm{He}$ is now an assistant-engineer in Jiangmen Power Supply Bureau, Guangdong Power Grid Co., Ltd. His major field of interest is planning of distribution network, distribution automation technology. 